\title{
Endovascular recanalization in acute ischemic stroke
}

\author{
Regionalized organization of care
}

Jeffrey L. Saver, MD

Correspondence \& reprint requests to Dr. Saver: jsaver@ucla.edu

Neurology ${ }^{\circledR}$ 2012;79 (Suppl 1):S3-S4
It is time to systematically plan for the next era in reperfusion therapy for acute ischemic stroke-the epoch of endovascular treatment.

Reperfusion therapies for acute arterial occlusions in different organ beds naturally evolve in 2 successive eras. In the first, IV thrombolysis (IVT) launches the reperfusion age, as the first useful, widely disseminated therapy, but its success is constrained by only modest recanalization rates. Then, in the second, endovascular recanalization techniques (ERTs) are developed that are far more effective at achieving reperfusion and supersede IVT alone to become the definitive, ongoing standard of care. This 2-stage pattern characterized the evolution of reperfusion therapy for both acute myocardial ischemia and acute limb ischemia. Reflecting the greater complexity and fragility of the brain and its vasculature, the evolution of acute ischemic stroke care has been slower but now can be seen to be also traversing this same historical path.

The decades from 1990 to 2010 were the era of IVT for acute ischemic stroke, as IVT evolved from untested therapy through clinical trial-validated intervention to standard therapy embedded in nationwide hospital systems of care.

We are now living and working in the early phase of the era of ERTs. The initial period of rapid, iterative technologic advance has been proceeding apace, as the endovascular armamentarium has expanded from intra-arterial fibrinolysis alone to corkscrew retrievers, suction thrombectomy, primary stenting, and stent retrievers. Randomized clinical trials of ERTs are advancing, fitfully but inexorably, from PROACT (Prolyse in Acute Cerebral Thromboembolism) 2 and MELT (Middle Cerebral Artery Embolism Local Fibrinolytic Intervention Trial) through the ongoing MR RESCUE (Mechanical Retrieval and Recanalization of Stroke Clots Using Embolectomy), IMS (Interventional Management of Stroke) 3, and THRACE (Trial and CostEffectiveness Evaluation of Intra-arterial Thrombectomy in Acute Ischemic Stroke) studies. The final step is to plan and then implement changes in the organization of care to provide patients with wide access to proven ERT interventions in routine practice. From this perspective, the studies and essays collected in the epidemiologic section of this supplement mark a historic moment: the first attempt to systematically understand the system and workforce transformations needed to make endovascular recanalization therapy widely available.

Rational planning for the coming era of endovascular care must begin by developing provisional estimates of the size and geographic distribution of the population that will be candidates for endovascular treatment. Two thoughtful essays in this supplement present first, ranging estimates. Zahuranec and Majersik provide a conservative projection, considering only candidates for pure intra-arterial fibrinolysis therapy in the 3- to 6-hour window. Zaidat and colleagues add 0 - to 3-hour patients for whom IV tissue plasminogen activator has failed and 6- to 8-hour patients who are candidates for mechanical embolectomy. Even the midpoint value at which Zaidat and colleagues arrive, 50,000 per year, may be conservative. The aging of the American populace means that the number of stroke patients presenting each year is likely to rise over the next decades. ${ }^{1}$ Also, validation and implementation of penumbral imaging selection will likely enable identification of additional patients, albeit modest in numbers, who are treatable in the 8to 24-hour window. ${ }^{2}$

To ensure these facilities provide access to ERTs to as much of the US population as possible, stroke systems of care will need to be formally organized at the regional level, with the prehospital ambulance system and multiple frontline primary stroke centers (PSCs) funneling appropriate patients, swiftly and surely, to comprehensive stroke centers (CSCs) that perform ERTs. ${ }^{3-5}$ ERTs require complex neuroangiographic capital equipment, expert neurointerventionalist physicians, and highly trained catheterization laboratory nurses, technologists, and anesthetists. Accordingly, ERTs will not be available at every hospital in the country, but instead at select secondary and tertiary hospitals. 
As suggested in the review by El Khoury et al. in this supplement, in the endovascular stroke therapy era, each state or county will need to set up an organized system of acute stroke care addressing prehospital, hospital, and legislative related factors that would improve access to the stroke chain of recovery. Emergency medical services agencies will train firstresponder emergency medical technicians and paramedics in stroke recognition, provide prearrival notification to receiving facilities that a stroke patient is inbound, and route all stroke patients to designated stroke centers. Telestroke telemedicine systems will enable neurologic and radiologic expertise to be extended to frontline hospitals so that $75 \%$ to $100 \%$ of all hospitals in a region can serve as PSCs, ensuring that all patients live in close proximity to a facility offering IV thrombolysis. Endovascular recanalization therapies will be offered at the 5\%-35\% of hospitals in a region that serve as CSCs, with rapid interfacility transfer procedures in place from PSCs to CSCs.

Are there enough skilled neurointerventionalists and is there enough money? Two articles in this supplement provide reassurance regarding these 2 fundamental requirements for build-out of regional ERT networks. Zaidat and colleagues carefully analyze a wide range of datasets to conclude that the neurointerventional physician workforce is already nearly sufficient in number to meet the demands of this new system of care. Michael Chen reviews data demonstrating that ERTs are highly cost-effective interventions; health policymakers and payors can be assured that the modest expense of setting up regionalized acute stroke systems of care is amply justified by the deaths and years of disability they will avert.

The ERT revolution in acute stroke care will be regionalized, and it has begun.

\section{AUTHOR CONTRIBUTIONS}

J.L.S. participated in drafting/revising the manuscript, study concept or design, and analysis or interpretation of data.

\section{DISCLOSURE}

Dr. Saver serves on the editorial boards of Stroke, Reviews in Neurologic Disease, Journal of Neuroimaging, and Journal of Stroke and Cerebrovascular Diseases; is an employee of the University of California (UC), which holds a patent on retriever devices for stroke; serves on scientific advisory boards, for which the UC Regents receive payments, for CoAxia, Inc., Concentric Medical, Talecris Biotherapeutics, Ferrer, AGA Medical Corporation, BrainsGate, PhotoThera, Ev3, and Sygnis Bioscience GmbH \& Co. K.G. is an unpaid site investigator in multicenter clinical trials sponsored by AGA Medical Corporation, Lundbeck Inc., and Ev3, for which the UC Regents received payments based on clinical trial contracts for the number of subjects enrolled; is an unpaid site investigator in the NIH IRIS, CLEAR, IMS 3, SAMMPRIS, and VERITAS multicenter clinical trials, for which the UC Regents receive payments based on clinical trial contracts for the number of subjects enrolled; and receives research support from the NIH (NINDS P50 NS044378 [PI] and NINDS U01 NS 44364 [PI]). Go to Neurology.org for full disclosures.

Received July 11, 2011. Accepted in final form September 7, 2011.

\section{REFERENCES}

1. Heidenreich PA, Trogdon JG, Khavjou OA, et al. Forecasting the future of cardiovascular disease in the united states: a policy statement from the American Heart Association. Circulation 2011;123:933-944.

2. Donnan GA, Baron JC, Ma H, Davis SM. Penumbral selection of patients for trials of acute stroke therapy. Lancet Neurol 2009;8:261-269.

3. Alberts MJ, Latchaw RE, Selman WR, et al. Recommendations for comprehensive stroke centers: a consensus statement from the Brain Attack Coalition. Stroke 2005; 36:1597-1616.

4. Acker JE III, Pancioli AM, Crocco TJ, et al. Implementation strategies for emergency medical services within stroke systems of care: a policy statement from the American Heart Association/American Stroke Association Expert Panel on Emergency Medical Services Systems and the Stroke Council. Stroke 2007;38:3097-3115.

5. Adams R, Acker J, Alberts M, et al. Recommendations for improving the quality of care through stroke centers and systems: an examination of stroke center identification options: multidisciplinary consensus recommendations from the Advisory Working Group on Stroke Center Identification Options of the American Stroke Association. Stroke 2002;33:e1-e7. 


\section{Neurology}

\section{Endovascular recanalization in acute ischemic stroke: Regionalized organization of care}

Jeffrey L. Saver

Neurology 2012;79;S3-S4

DOI 10.1212/WNL.0b013e318269596d

\section{This information is current as of September 24, 2012}

\section{Updated Information \&} Services

References

Citations

Subspecialty Collections

Permissions \& Licensing

Reprints including high resolution figures, can be found at: http://n.neurology.org/content/79/13_Supplement_1/S3.full

This article cites 5 articles, 4 of which you can access for free at: http://n.neurology.org/content/79/13_Supplement_1/S3.full\#ref-list-1

This article has been cited by 1 HighWire-hosted articles: http://n.neurology.org/content/79/13_Supplement_1/S3.full\#\#otherartic les

This article, along with others on similar topics, appears in the following collection(s):

All Cerebrovascular disease/Stroke

http://n.neurology.org/cgi/collection/all_cerebrovascular_disease_strok e

All epidemiology

http://n.neurology.org/cgi/collection/all_epidemiology

Information about reproducing this article in parts (figures,tables) or in its entirety can be found online at:

http://www.neurology.org/about/about_the_journal\#permissions

Information about ordering reprints can be found online:

http://n.neurology.org/subscribers/advertise

Neurology ${ }^{\circledR}$ is the official journal of the American Academy of Neurology. Published continuously since 1951, it is now a weekly with 48 issues per year. Copyright Copyright @ 2012 by AAN Enterprises, Inc.. All rights reserved. Print ISSN: 0028-3878. Online ISSN: 1526-632X.

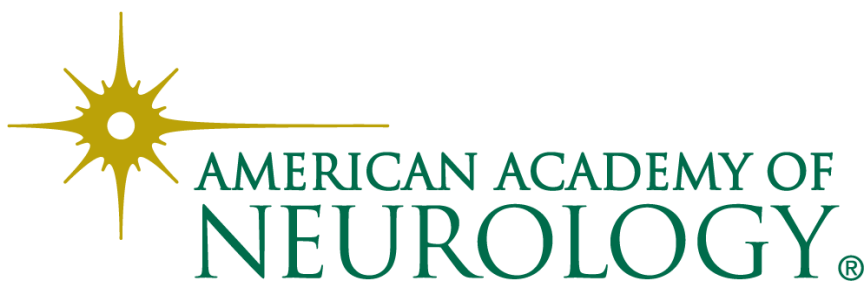

